\title{
LA TEORÍA DE LA CONSTITUCIÓN EN JAMES BUCHANAN: HACIA UN MODELO DE ECONOMÍA CONSTITUCIONAL
}

\author{
Constitutional theory in James Buchanan: \\ Toward a model of constitutional economics
}

\author{
GABRIEL MORENO GONZÁLEZ \\ Universidad de Valencia \\ Gabriel.Moreno-Gonzalez@uv.es
}

\begin{abstract}
Cómo citar/Citation
Moreno González, G. (2017).

La teoría de la Constitución en James Buchanan:

hacia un modelo de economía constitucional.

Revista de Estudios Políticos, 177, 57-88.

doi: https://doi.org/10.18042/cepc/rep.177.02
\end{abstract}

Resumen

El presente artículo tiene por objeto el análisis de la teoría constitucional del Premio Nobel de Economía James M. Buchanan a través de la exégesis de sus principales aportes doctrinales, desgranando aquellos principios que revisten interés para la doctrina constitucional y que pueden servir de fundamento teórico a la constitucionalización de los mecanismos de gobernanza económica en Europa. Se intentará demostrar, con ello, que el autor elaboró una completa y sui generis teoría de la Constitución desde el paradigma neocontractualista de la década de los setenta y bajo el parámetro de su radical individualismo metodológico, que le llevó a defender nuevas categorías constitucionales y proposiciones normativas no exentas de contradicciones y críticas.

\section{Palabras clave}

Economía constitucional; teoría de la elección pública; catalaxia; ordoliberalismo; gobernanza económica. 


\begin{abstract}
This article contains an analysis of the constitutional theory of Nobel Prize winning economist James M. Buchanan. It proceeds through an explanation of his main doctrinal inputs, breaking down those principles which are of interest for constitutional doctrine, and which can be used as a theoretical foundation for the "constitutionalisation" of economic governance mechanisms in Europe. The paper shows that Buchanan developed a complete and sui generis theory of Constitution from the neo-contractualist paradigm of the 70s, and under the parameter of his methodological individualism, which led him to defend the new constitutional categories and normative proposals, which were also not exempt from contradictions and criticisms.
\end{abstract}

\title{
Keywords
}

Constitutional economics; Public Choice Theory; catalaxia; ordoliberalism; economic gobernance. 


\section{SUMARIO}

I. INTRODUCCIÓN. II. EL GIRO HACIA EL ESTADO: 1. El nuevo paradigma contractualista. III. ENTRE LA ANARQUÍA Y EL LEVIATÁN: EL MODELO BUCHANIANO DE CONTRATO SOCIAL: 1. De Hobbes a Nozick. 2. El abandono de la selva. 3. La unanimidad frente a la tiranía de las mayorías. IV. LA CONSTITUCIÓN, GARANTE DE LA ECONOMÍA DE LIBRE MERCADO: 1. El homo economicus como modelo explicativo en el que fundar la Constitución. 2. El Leviatán administrativo. V. LA SUPERACIÓN CONSTITUCIONAL DEL CONFLICTO: LÍMITES JURÍDICOS A LA INTERVENCIÓN DEL ESTADO EN LA ECONOMÍA: 1. Worst case situations: hipótesis Leviatán. 2. Los límites al poder fiscal del Estado. VI. CONCLUSIÓN. BibLIOGRAFía.

Se comprendió que vivir sometido a la voluntad de otro es causa de todas las miserias humanas, lo que obligó a acogerse al patrimonio de las leyes, que permite a la gente conocer de antemano sus deberes y las sanciones que comporta su transgresión.

Richard Hooker

\section{INTRODUCCIÓN}

En los últimos años, y al calor de la coyuntura económica, se ha incorporado al debate doctrinal el análisis de la constitucionalización de los llamados mecanismos de gobernanza económica que limitan el poder presupuestario del Estado (Álvarez Conde y Souto Galán, 2012). Y es que la restricción jurídico-constitucional del déficit y el endeudamiento público ha encontrado acomodo tanto en el seno del proceso de integración europea, mediante la aprobación del Tratado de Estabilidad, Coordinación y Gobernanza, como en los interdependientes ordenamientos estatales (Enériz Sánchez, 2013). Prueba de ello es la aprobación, en 2011, de la reforma del artículo 135 de la Constitución española para incorporar al más alto nivel jurídico la estabilidad presupuestaria y la limitación del endeudamiento, que viene a cristalizar una traslación en las clásicas formulaciones de la "constitución económica» hacia una mayor restricción jurídica del intervencionismo estatal en el mercado, traslación que puede encontrarse desde el plano teórico en la revitalización del viejo ideario 
liberal de la Europa de posguerra y que alcanza su cenit en el corpus teórico del Premio Nobel de Economía James M. Buchanan, cuya obra es esencial para entender los fundamentos explicativos de la constitucionalización de la estabilidad presupuestaria y de los mecanismos de gobernanza a ella aparejados.

A fin de extraer los elementos de naturaleza constitucional de la obra del economista norteamericano, analizaremos en primer lugar el cambio epistemológico radical que implica el surgimiento y afianzamiento del ordoliberalismo en Europa, que derivará en una renovada preocupación por el diseño estatal desde el prisma económico de la garantía del libre mercado. Como veremos, este giro en el devenir teórico liberal se incardinará en la renovación del paradigma contractualista y su resurgimiento en la década de los setenta, donde la nueva preocupación por el Estado se canalizará a través de la creación ex novo de modelos explicativos del orden social y jurídico con pretensión de globalidad. Partiendo de este neocontractualismo, abordaremos las implicaciones teóricas del contrato social para el marco constitucional en Buchanan, sus principios vertebradores y la consideración que del individuo y del Estado tiene el autor. De ellas, por último, derivaremos las proposiciones de carácter normativo y prescriptivo que se infieren de la obra buchaniana y del subsiguiente programa de la economía constitucional, dedicando especial atención a la incorporación de restricciones constitucionales al poder fiscal y presupuestario del Estado.

\section{EL GIRO HACIA EL ESTADO}

A pesar de lo que pudiera parecer ab initio, y en contra de la idea generalizada que se tiene de la materia desde sectores no académicos, el resurgimiento de las teorías económicas liberales desde el fin de la Segunda Guerra Mundial y su posterior desarrollo y consolidación tiene como uno de los ejes centrales de análisis al Estado y su realidad jurídica (Laval y Dardot, 2013: 69-82). El «neoliberalismo», así llamado en su bautismo de fuego de 1938 en el Coloquio Lippmann de París (Jackson, 2010), se erige como una compleja convergencia de movimientos y corrientes de pensamiento que, lejos del carácter peyorativo que en algunos ámbitos se le otorga, constituye una madeja coherente y elaborada cuyas raíces se asientan en categorías clásicas de la filosofía política (cfr. Escalante Gonzalbo, 2016). Aunque las contradicciones internas de tan amplio movimiento han sido evidenciadas por multitud de autores (cfr. Hoevel, 2014: 46 y ss.), existe una serie de ejes en torno a los cuales la unanimidad es manifiesta y sobre los que parten las diferentes escuelas y modos de entender el neoliberalismo. Uno de ellos, y quizá el más destacado, como decimos, es la relevancia que se le otorga al Estado y el papel central que 
desempeña en el sistema económico, constatación que se convierte en parámetro esencial de todo análisis neoliberal, desde el ordoliberalismo alemán, la escuela austríaca o los neoclásicos de Chicago, a la menos conocida Escuela de Elección Pública (public choice), en la que se encuadra James Buchanan.

El propósito originario del neoliberalismo en sus comienzos durante el periodo de entreguerras fue la reconstrucción teórica de los ideales liberales, dados entonces como desvirtuados y prácticamente perdidos (Gauchet, 2007: 64 y ss.). En medio de una Europa sumida en Estados intervencionistas que habían expandido exponencialmente su radio de acción en los últimos decenios, cuando no directamente en Estados abiertamente totalitarios, los nuevos liberales pretendían recuperar la tradición de una res publica limitada que sirviera de marco en el que los individuos pudieran actuar con la mayor libertad posible. Pero eran conscientes de que Occidente ya no era como en los tiempos de Bentham o Stuart Mill, que las sociedades industriales se habían complejizado en grado sumo y que, por si fuera poco, buena parte de la desnaturalización del liberalismo se debía a errores internos de la propia doctrina que había que reorientar (cfr. Lippmann, 2014). Sobre todo, centraron sus críticas en la dejadez liberal a la hora de analizar la realidad estatal, que habría permitido que los problemas derivados de la industrialización y del vertiginoso crecimiento económico se canalizaran a través del reformismo social y de la asunción por parte del Estado de las externalidades negativas (Spencer, 1984: 16-28). La creencia ciega en el laissez faire manchesteriano y en la idea de que el mercado, que ofrece las condiciones óptimas para el libre intercambio entre quienes disfrutan de independencia jurídica, es una realidad natural e irreversible, no sujeta a condicionamientos externos e institucionales, dejaba abierta la puerta a través de la cual el reformismo social estatalista entraba con inusitada fuerza (Brennetot, 2015: 30-39).

Esa «ilusión naturalista» en torno al mercado, como lo llamó el propio Walter Lippmann (Laval y Dardot, 2013: 69-75), se considera como el principal error ínsito en el liberalismo, ante el cual los neoliberales pretenden reconducir todo su andamiaje para poder seguir salvaguardando, con renovado vigor e intensidad, los ideales de libertad. Y para abandonar tal «ilusión» ingenua los primeros neoliberales se giran, metodológica y epistémicamente, hacia el Estado. El mercado no es algo natural, que funcione sin necesidad de marcos institucionales y jurídicos, no es inherente a los procesos económicos, sino que su supervivencia depende en todo momento del diseño estatal que se establezca. Si el Estado se ha convertido en un «monstruo» en la primera mitad del siglo XX, dicen, es porque los liberales clásicos le han «dejado hacer» en la confianza de que el mercado seguiría existiendo al margen de cualquier contexto institucional (Bonefeld, 2013: 238 y ss.). De ahí que la escuela del ordoliberalismo alemán, una de las primeras en intentar superar dicha creencia, centre sus 
esfuerzos teóricos en la reconstrucción de un orden de libre competencia en la devastada Alemania de posguerra desde y por el Estado (cfr. Marcos de la Fuente, 1978, y Gerber, 1994: 30 y ss.). Este no ha de ser un agente indómito que sustituya al mercado, sino el elemento que proporcione las condiciones jurídicas en las cuales pueda desenvolverse con estabilidad la competencia y la libertad. La "política de ordenamiento», como la llaman, es el eje central de su teoría: el tratamiento jurídico-estatal del mercado, el diseño del marco institucional más favorable a la libre competencia entre los agentes económicos en un espacio de libertad e independencia (Erhard, 1994: 90).

Este cambio de perspectiva hacia el Estado que crea el neoliberalismo, esta toma de conciencia de su importancia en la garantía de las condiciones de mercado, la comparten no solo los ordoliberales alemanes que más cerca y con mayor profundidad vivieron la revitalización del mercado en la praxis, sino también, aunque con diferentes grados de intensidad en la adhesión, los austríacos de Mises y Hayek, la Escuela de Chicago de George Stitler y Milton Friedman y, sobre todo, la public choice de James Buchanan, que perfeccionará el vuelco analítico mediante la elaboración de una teoría holística del Estado desde una base contractualista. De ahí que autores como Vanberg tracen una línea directa de influencia entre el giro copernicano del ordoliberalismo en cuanto al Estado y la innovadora elaboración constitucional de Buchanan (Vanberg, 1988: 17-31 y 2005: 23-49).

\section{EL NUEVO PARADIGMA CONTRACTUALISTA}

En el contexto descrito no es de extrañar que los economistas incardinados de alguna u otra forma en el amplio y diverso campo neoliberal hagan incursiones en la teoría política, puesto que la renovada preocupación por el Estado no puede ser solo analizada desde el prisma económico. La economía y sus instrumentos analíticos no pueden agotar, ni mucho menos, el ya de por sí proceloso ámbito de estudio del Estado y su naturaleza. De hecho, en teóricos como Hayek, tan relevantes para el desarrollo de la doctrina neoliberal, los criterios analíticos que más abundan son los propios de la filosofía y teoría políticas, y hasta de la filosofía de la historia (cfr. Hayek, 2014).

En este sentido, el neoliberalismo no es ajeno a la reaparición del contractualismo a principios de los años setenta (Vallespín, 1985). Si el Estado ocupa un lugar preeminente en cualquier doctrina política, la explicación de su aparición y la propia justificación de su existencia han de cobrar especial relevancia, de ahí el resurgimiento del contractualismo a principios de la década mentada al calor de nuevos modelos holísticos explicativos de la realidad (cfr. Porras Nadales, 1984). La publicación en 1971 de $A$ theory of justice, de John Rawls (1979), inauguró un debate en el seno de la academia que recuperó el 
interés por las teorías de lo social fundadas en el convencionalismo. Estas, que tienen como referentes modernos a Thomas Hobbes, John Locke o Inmmanuel Kant, siempre han partido de la introducción, como estadio previo a la existencia del Kratos, de un supuesto "estado de naturaleza» que es abandonado en aras de una mayor seguridad, felicidad o bienestar por el conjunto de los individuos, quienes, de mutuo acuerdo, establecen unas reglas mínimas de convivencia y una unidad política bajo la cual aquellas han de regirse, instaurando, a través de un contrato social consensuado, el fundamento del nuevo poder (Pastore, 2012). En el caso de Rawls, el contractualismo le sirve de marco teórico en el que asentar su pretendida reconciliación de los principios de igualdad y de libertad a partir de una idílica situación de elección previa (posición original). En ella, los individuos tomarían las decisiones fundantes del orden político atendiendo al desconocimiento que tienen sobre su propio futuro (velo de la ignorancia) y cediendo cooperativamente para establecer un sistema justo que incorpore mecanismos de redistribución de la riqueza y, al mismo tiempo, respete las libertades individuales. Por tanto, el momento constituyente rawlsiano aleja la posibilidad de retornar a un inseguro "estado de naturaleza» mediante la decisión consensuada y enraizada en la ignorancia del futuro (y por ende, en el miedo) que justifica, axiológicamente, la intervención del Estado en la garantía redistributiva de una igualdad de partida (Martínez García, 1985).

Los planteamientos de Rawls, vertidos en un contexto de renovado interés por el anarquismo en Estados Unidos (Hogarty, 1972), provocarán la defensa de elaboradas teorías contrarias a la socialdemocracia y al Estado social que el autor norteamericano pretendía legitimar. Así, apenas tres años después de la publicación de la obra magna de Rawls, Robert Nozick presentará como contestación su propio modelo neocontractualista en la ya célebre obra Anarquía, Estado y Utopia, donde defiende un nuevo contrato social que funde un Estado mínimo lockeano respetuoso con los derechos propios del liberalismo y donde no haya lugar para la redistribución (Nozick, 1988). Frente a los anarcocapitalistas como David Friedman o Rothbard (1973), Nozick sí defiende la existencia del Estado, pero limitado hasta el extremo de solo deberse a la garantía de los derechos individuales.

Por su parte, Buchanan se incorporará al debate neocontractualista en 1975 con una visión propia diferente tanto de la socialdemócrata de Rawls como de la minarquista de Nozick. Quien posteriormente recibiría el Premio Nobel de Economía se situará, desde una compleja elaboración teórica, en la perspectiva neoliberal iniciada en el Coloquio Lippmann ${ }^{1}$. Si aquí los

Algunas referencias indirectas a la obra de Lippmann pueden encontrarse en el mismo Buchanan (2009: 238). 
referentes neoliberales comenzaron el giro analítico hacia el Estado, impulsado también en la praxis por los ordoliberales alemanes, en Buchanan esta renovada toma en consideración de la realidad estatal se completará gracias a su formulación contractualista que, aun asemejándose en algunos aspectos a las contribuciones de Rawls y Nozick, cobrará autonomía y relevancia hasta llegar a conformar la rica escuela de pensamiento de la public choice y la economía constitucional.

\section{ENTRE LA ANARQUÍA Y EL LEVIATÁN: EL MODELO BUCHANIANO DE CONTRATO SOCIAL}

Antes de adentrarnos en la teoría constitucional de James Buchanan hemos de analizar cuáles son los fundamentos que le sirven de soporte en tal construcción, y más habida cuenta de la naturaleza holística de su pensamiento, donde no existen elementos separados o independientes de un todo coherente que hunde sus raíces en su sui generis modelo contractualista, no exento, sin embargo, de influencias externas. Y siempre, claro está, teniendo en cuenta que su construcción es una hipótesis del «surgimiento del Estado como si» hubiera nacido a imagen y semejanza de lo que, sin pretensiones descriptivas, Buchanan desarrolla (Brennan y Buchanan, 1987: 27).

\section{DE HOBBES A NOZICK}

Como ha puesto de manifiesto Casas Pardo, en su concepción filosófica y del estado de naturaleza Buchanan bebe directamente de Hume, Smith y sobre todo Hobbes, el autor más citado en sus obras, para negar la supuesta existencia de derechos individuales previos al contrato social (Casas Pardo, 2011: 236238 y 247). A diferencia de Locke y de Nozick, en la «selva hobbesiana» de Buchanan reina la más pura anarquía y la guerra de todos contra todos, sin respeto alguno por esferas pretendidamente iusnaturales. Acciones productoras, depredatorias y defensivas se alternan en la actividad de los individuos precontractuales, en medio de un contexto de inseguridad general que deriva en una manifiesta insatisfacción que solo puede ser superada a través del convencionalismo. No obstante, a diferencia de Hobbes, en Buchanan el contrato no crea la sociedad civil, preexistente a cualquier acuerdo, sino la organización jurídico-política a través de la cual esa sociedad ya viviente se dota de unas reglas vinculantes para superar la lucha cruenta y poder así, con ello, centrarse en los esfuerzos cooperativos y en el intercambio de los excedentes (Puy Fraga, 1996: 84 y ss.). La distinción no es baladí: en Hobbes no existe traspaso de la concepción previa al poder político instaurado, en Buchanan, sí. El clásico inglés crea 
el poder político ex nibilo para asegurar a la sociedad de la destrucción que vivía en la selva de la naturaleza (cuando no era ni sociedad), mientras que en Buchanan la perspectiva constitucionalista intenta rebajar las actitudes no cooperativas derivadas de la inseguridad anárquica, pero no superar por completo las tendencias cooperativas de mutuo intercambio pacífico que sí se dan en la sociedad precontractual. Ambos comparten una visión pesimista de un estado de naturaleza (homo homini lupus) que les sirve de hipótesis en la que fundar sus pretensiones normativas posteriores, pero el cierre del modelo es cualitativamente diferente: para Hobbes, el absolutismo del poder que anula la anarquía; para Buchanan, el poder constitucionalmente limitado que potencia las tensiones anárquicas de cooperación ínsitas en el individuo y que diluye y atenúa su predisposición también connatural a la depredación (Pérez Bermejo, 2000). No por nada Buchanan siempre se consideró a sí mismo, en el fondo y desde el prisma ideal de la pura pretensión filosófica, como un melancólico anarquista, consciente, empero, de las limitaciones de dicha teoría y de la irrealidad de su utopía (Buchanan, 1974: 915).

En la exégesis del contractualismo buchaniano también podemos encontrar otra notable diferencia con Hobbes que lo acerca a Rawls. Aunque comparte con el autor del Leviatán un intenso y decidido individualismo metodológico, como veremos más adelante, Buchanan no se deja arrastrar por el formalismo positivista de la sumisión a un poder indómito. En él pervive la búsqueda en la formulación del contrato social de un ideal de justicia no exógeno a la propia decisión consensual, tal y como se da en la obra rawlsiana (Buchanan, 2009: 253-254). Los individuos, reunidos en el ágora pre-contractual, desean una solución y una salida constituyentes que se adecuen a una pretensión de justicia decidida en conjunto, no derivada de abstracciones valorativas ajenas al marco decisorio. Siguiendo a Hayek, Buchanan recela de los ideales-tipo que sirven de guía a las sociedades desde la altura de sus esencialismos ahistóricos, pues su aterrizaje en la praxis siempre devendría en imposiciones contrarias a la libertad de los individuos que los comparten.

$\mathrm{Al}$ mismo tiempo, Buchanan se acerca a Nozick en su temor, constante, a la extralimitación del Estado. Como su compatriota, cree que el poder político tiende siempre a la expansión y que ello puede anular las libertades individuales protegidas en el contrato, por lo que la lupa de su análisis contractualista se fijará denodadamente en la limitación del poder estatal (cfr. Buchanan, 1987, y Vanberg, 2014: 18-38). No obstante, para Buchanan este no ha de circunscribirse únicamente a una esfera iusnatural y previa de derechos, como en Nozick, sino a los mandatos que en el momento constituyente la sociedad, unánimemente, le dicte y obligue, los cuales pueden y deben ser, como veremos, más amplios que el minarquismo de Anarquía, Estado y Utopía, y permitir, al tiempo, tímidos mecanismos de redistribución. 


\section{EL ABANDONO DE LA SELVA}

Para Buchanan, en la anarquía hobbesiana los esfuerzos depredatorios y defensivos de los individuos conllevan un coste difícil de asumir y acaban afectando a la producción. La guerra de todos contra todos es el peor de los contextos donde los intercambios cooperativos pueden darse, estando siempre los excedentes al albur de la inseguridad y de las injusticias. Por ello, es comprensible que los individuos abandonen ese estado mediante un pacto de desarme, de mutuo acuerdo, que permita centrar sus esfuerzos en aumentar la producción y el rendimiento excedentario a ella aneja. No obstante, y a diferencia de múltiples contractualistas (Hobbes o Rawls), para Buchanan ese contrato no se firma entre iguales, sino entre desiguales. Cada cual, dependiendo de sus aptitudes naturales, es capaz de desarrollar su personalidad y de producir bienes de forma distinta, y de esta cruda pero realista verdad parte el pacto buchaniano. No se llega a él desde la abstracción de la igualdad, puesto que esta solo puede ser establecida (impuesta, en palabras del filósofo) por el acuerdo constituyente. En el estado de naturaleza y, por tanto, en el momento previo al pacto y conformador del mismo (precontractual), los individuos mantienen las diferencias connaturales a sus potencialidades, vertiéndolas al objeto del consenso. Como dice el propio Buchanan: «Vivimos en una sociedad de individuos, no de iguales» (2009: 30). De hecho, el acuerdo nunca podrá tener por misión el igualitarismo en la medida en que las partes "firmantes» desearán mantener sus peculiaridades caso de ser beneficiosas. Para el talentoso, el inteligente, el hábil o el ya rico, el interés que pudiera pesar sobre la instauración de mecanismos redistributivos sería nimio. Por el contrario, para quienes resultan perjudicados por la «distribución natural» de las capacidades (Bush y Mayer, 1973) o, simplemente, por el libre juego de las luchas depredatorias en la selva hobbesiana, el abandono de esta a través de una convención que les beneficie o atenúe al menos su situación se puede convertir en el epicentro de sus demandas (Buchanan, 1975: 121126). Si la polaridad descrita se mantuviera sine die, dice Buchanan, el pacto de desarme nunca se alcanzaría y todas las partes se seguirían viendo perjudicadas dada la inseguridad reinante y la desviación de no pocos esfuerzos a la defensa o a la depredación. El acuerdo mutuo «facilita el intercambio mutuo entre personas» (Buchanan, 2009: 38). Es por ello que, en una situación de decisión originaria, todos los miembros del grupo son proclives a un acuerdo que satisfaga a la totalidad y que implique el desarme absoluto. Para evitar situaciones como las descritas en el dilema del prisionero (Puy Fraga, 1996: 107) y que haya individuos que perseveren en su actitud combativa y destructiva al margen del acuerdo social, este ha de ser lo más inclusivo posible y basarse en la unanimidad. El pacto, el contrato, ha de contar con el consentimiento de todos los que conforman la sociedad, incluso de aquellos con posturas completamente polarizadas. 
Además, Buchanan parte en todo momento de la existencia constatable de bienes públicos que han de ser producidos y gestionados por el Estado, el cual no ha de limitarse única y exclusivamente a sus funciones de protección y salvaguarda de los términos del pacto (como en Nozick). De hecho, la seguridad, causa por la que el contrato se celebra, no deja de ser en sí misma un bien público más que hay que desplegar y administrar. A fortiori, se constatan más bienes que por su propia naturaleza revisten el carácter de públicos, como los monopolios naturales o aquellos que son necesarios para el afianzamiento del consenso. En efecto, en aras de conseguir un estable pacto de desarme, los más beneficiados por sus capacidades naturales en la posición natural han de ceder en parte de sus pretensiones, pudiendo llegar a consentir tímidos mecanismos de redistribución no predatorios, los cuales no solo coadyuvarían a integrar al pacto a los elementos más disconformes, sino también a aumentar el bienestar general y aun la riqueza de esos mismos privilegiados que ceden en sus intereses más directos. La posición relativa de todos los individuos puede verse beneficiada y reforzada, conservando la desigualdad inicial, pero sobre el eje de magnitudes más elevadas, sin que los citados privilegiados tengan que ver dinamitada su posición.

Así las cosas, la distribución inicial que se da en el estadio anárquico previo al momento constituyente es la que determina en buena medida el resultado de este, el contrato social, mediante la traslación del equilibrio de fuerzas de la anomia al conjunto normativo resultante del pacto. Traslación que, sin embargo, no es literal, puesto que la existencia de bienes públicos implica la necesidad de vertebrar mecanismos de decisión sobre la producción y administración de los mismos con la posibilidad, consabida, de que puedan a posteriori alterar el equilibrio inicial con su expansión. De ahí la preocupación de Buchanan en el diseño de los mecanismos postconstitucionales ${ }^{2}$ desde el propio momento constituyente, en tanto en cuanto pueden ser medios a través de los cuales se beneficien a costa de los privilegiados aquellos que, por sus aptitudes, no deberían hacerlo (Puy Fraga, 1996: 114 y ss.).

\section{LA UNANIMIDAD FRENTE A LA TIRANÍA DE LAS MAYORÍAS}

Como hemos visto, Buchanan elabora su modelo neocontractualista con base en el consenso de los individuos que, cediendo mutuamente (bienes públicos determinados), pero sin abandonar sus respectivas situaciones originarias,

2 En Buchanan, postconstitucional o preconstitucional son sinónimos de postcontractual o precontractual, aunque la combinación de dichos términos pueda llevar a no pocos equívocos. 
alejan la incertidumbre de la selva hobbesiana y los costos (depredatorios y defensivos) que esta llevaba aparejada. Ahora, con el establecimiento de una sociedad también política y de un poder limitado que haga cumplir el pacto sinalagmático, los individuos pueden centrarse en sus esfuerzos productivos personales en los marcos de cooperación e intercambio de bienes y servicios. No obstante, la creación del aparato estatal como árbitro-tercero que haga cumplir el pacto y provea de bienes públicos a la sociedad conlleva per se una serie de riesgos que hay que afrontar desde apriorismos, riesgos que han constituido ininterrumpidamente la preocupación mayor en el seno del liberalismo. Porque, adelantándonos en el desarrollo argumentativo, si la existencia del Estado es para Buchanan consustancial a las garantías del libre mercado tal y como se entiende desde el parteaguas neo-ordoliberal, su diseño ha de atender a la salvaguarda de dichas garantías. Pero, mientras que los ordoliberales llevarán a cabo su construcción desde la altura de sus mismos modelos teóricos valorativos, Buchanan lo intentará hacer desde el interior del proceso decisional propio del momento constituyente $\mathrm{y}$ atendiendo a la Constitución como norma fundante.

En este sentido, para el autor de El cálculo del consenso (Tullock y Buchanan, 2015) la esencia de la democracia no residiría en el triunfo de las decisiones de la mayoría frente a las minorías, sino en el respeto ad sumum de la voluntad de todos y cada uno de los miembros de la colectividad. Su individualismo metodológico le lleva a rechazar de plano que los mecanismos de decisión puedan servir para coartar la libertad y los derechos del individuo, aunque solo sea uno el perjudicado por la decisión del conjunto del grupo. De lo contario, dice Buchanan, las mayorías utilizarían continuamente tales mecanismos para llevar a cabo las prácticas depredatorias propias de la selva hobbesiana, consiguiendo ilícitamente aquello que no les corresponde y arrebatándoselo a quien, con justo título, sí le pertenece. Como afirma el propio premio Nobel: «[las mayorías] le quitan bienes al individuo en contra de su deseo expreso. Se ejerce aparentemente sobre él una coacción similar a la que ejerce el matón que se lleva su billetera en Central Park» (Buchanan, 2009: 74). La situación de equilibrio natural que describíamos antes no se trasladaría así, ni con matices, a través del pacto político originario. De suerte tal que el proceso constituyente, que el momento precontractual donde se establece el escenario jurídico postcontractual, ha de ser protagonizado por la unanimidad de los miembros de la sociedad si se quiere preservar la soberanía del individuo en el proceso democrático. Con la garantía de la unanimidad en la decisión constituyente, cuya relevancia Buchanan se la debe al economista Knut Wiksell (Brennan y Buchanan, 1987: 29; Buchanan, 2009: 68 y Elósegui, 1993: 37), se está legitimando hasta el extremo el texto constitucional fundante del orden político y evitándose, con ello, la incorporación de medios o técnicas de «rapiña» redistributiva alejados del mínimum necesario para 
alcanzar el consenso. El diseño de los mecanismos postconstitucionales de decisión, en la medida en que vertebra las futuras decisiones de las mayorías, cobra así especial relevancia para el planteamiento individualista de Buchanan.

Siguiendo a Elster, podemos afirmar que la constitución buchaniana son las cuerdas en las que Ulises se ata antes del canto de las sirenas (Elster, 2009). El momento constituyente ha de reflejar el precompromiso unánime de todos los elementos del grupo de no vulnerar siquiera ni el más nimio de los derechos de un individuo aislado, desde el apriorismo consensual de un estadio precontractual que desea el abandono de la anomia natural. Como dicen Buchanan y Brennan: "La condición necesaria para garantizar al individuo que el Estado nunca le originará perjuicios o daños, a la vez que esta garantía incluye a todos los ciudadanos en igual manera, es el requisito de que todas las decisiones del Estado se tomen mediante la regla de la unanimidad» (1987: 29). Cuando Ulises, por continuar la metáfora de Elster, ordena al resto de los miembros de su tripulación que lo aten al mástil, está previendo el incumplimiento futuro del deseo actual de no sucumbir a las sirenas. Cuando la unanimidad del grupo decide dotarse de una norma, de unas cuerdas que la aten, está anticipando los más que probables incumplimientos por parte de subgrupos aislados o coordinados del pacto fundante del orden, con el peligro que ello conlleva de regresión al estado de naturaleza hobbesiano y a la guerra de todos contra todos que se pretende evitar. En la construcción de Buchanan hacen falta sólidas y férreas cuerdas que fijen el acuerdo unánime para que la agregación de preferencias que cristalice no salte por la borda al primer intento de rotura, y esas cuerdas las proporciona el texto constitucional gracias a la especial estabilidad de su andamiaje. Siguiendo al propio Buchanan bajo el epígrafe de «La democracia desencadenada»: «La democracia puede convertirse en su propio Leviatán a menos que se impongan límites constitucionales y se los haga cumplir» (Buchanan, 2009: 235). Y es que la Constitución, al ser una norma superior al devenir de la política diaria y ser para esta indisponible, tiene por su propia naturaleza una tendencia connatural a la permanencia que le dota de una contundencia sin igual. No obstante, en el contexto de la economía constitucional ello ha sido visto por algunos autores (Musgrave, 1993: 201-205) como una muestra del carácter conservador del pensamiento de Buchanan por defender, a ultranza, la estabilidad de la norma normarum.

\section{LA CONSTITUCIÓN, GARANTE DE LA ECONOMÍA DE LIBRE MERCADO}

Como indicábamos al inicio, para los ordoliberales la garantía del libre mercado y de las condiciones en las que este se desenvuelve solo puede darse 
a través de la determinación de un orden jurídico funcional a tal objetivo. Siguiendo a Erhard, «la tarea de instituir un marco económico únicamente puede ser competencia del Estado. Es tarea del Estado dictar las reglas del juego en la economía, del mismo modo que previamente también es tarea suya la instauración de la constitución social, económica y política de un país. [...] La tarea del Estado tiene que ser la de velar por la libertad de la competencia» (1994: 113).

Pues bien, esta relevancia y funcionalidad del orden jurídico para con el libre mercado Buchanan las verterá íntegramente en su Constitución-tipo asentada en la unanimidad del momento preconstituyente, y para que puedan llegar a tener la virtualidad que de ellas se espera, el diseño a priori de los procedimientos de toma de decisiones postconstitucionales cobrará especial importancia en los planteamientos buchanianos, que girarán en torno a la consideración sui generis del propio valor del individuo y de sus potencialidades.

\section{EL HOMO ECONOMICUS COMO MODELO EXPLICATIVO EN EL QUE FUNDAR LA CONSTITUCIÓN}

En efecto, todo planteamiento holístico que se pretenda sobre la realidad social, ya sea desde el derecho o la economía (y más, como en este caso, desde la economía constitucional), necesita una subteoría pretendidamente descriptiva del comportamiento humano. Huelga decir que las normas han de aplicarse al conjunto de los individuos que son, al fin y al cabo, sus destinatarios, por lo que desde una teoría jurídico-económica con pretensión de globalidad la consideración sobre tales individuos tiene que cobrar especial relevancia. Y más cuando para esa teoría uno de los ejes vertebradores esenciales es el diseño a priori del ordenamiento jurídico atendiendo a la compleja realidad social sobre la que se proyecta, con singular incidencia en la virtualidad de la norma constitucional.

Así, Buchanan y el programa de la economía constitucional defenderán la traslación del modelo de homo economicus de la escuela neoclásica al análisis jurídico-constitucional, en uno de los planteamientos más controvertidos de la public choice (Puy Fraga, 1996: 37 y ss., y Mitcher, 1987: 42). Si, como decimos, para Buchanan el individualismo metodológico es el parámetro analítico por excelencia, la idea de que el individuo se guía únicamente por la maximización en todo momento de sus beneficios aparece como uno de los ejes conceptuales básicos de su doctrina. En este sentido, se defiende por parte del autor de Virginia la idea propia de las escuelas económicas del XIX, de que cada individuo es en sí mismo considerado un ente autónomo que decide siempre atendiendo a su propio interés, elaborando desde su capacidad ontológica previa una «función de preferencias» donde modula estas en función 
del contexto (público y privado) de circunstancias que rodean al intercambio. Ello presupone además la imputación automática de racionalidad a todos los individuos y a todas las decisiones que lo acompañan, prejuicio que comparte con otros individualistas como Rawls, a lo que hay que sumar la defensa de la "concepción subjetiva del valor» (Buchanan, 1993: 141 y ss.). En efecto, no solo la sociedad es para Buchanan un conjunto de individuos que cooperan dentro de un contexto normativo dado e intercambian bienes con base en la maximización constante de sus intereses particulares, sino que ese mismo intercambio está presidido también por la valoración individual que se hace de sus bienes, los cuales dejan de tener valor objetivo alguno (valor de uso, en la escuela marxista), para tener única y exclusivamente un valor relativo que depende de la satisfacción subjetiva de los intereses individuales (valor de cambio). La multiplicidad de estos, en el seno de sociedades cada vez más complejas y numerosas, aleja en consecuencia la posibilidad de planificación alguna por parte del Estado o de agentes cualificados, en la medida en que nunca podrán administrar la información suficiente (la plenitud de valoraciones individuales sobre los conjuntos alternativos de bienes) para poder dirigir, conscientemente, la economía y los mecanismos de cooperación voluntaria que en ella se desenvuelven (Hayek, 2011).

No obstante, al igual que hace con su modelo contractual y la «existencia» del previo estado de naturaleza, para Buchanan este parámetro del homo economicus es una hipótesis, una abstracción, que pretende aproximarse a lo que el individuo-tipo realiza en cada ocasión, y no una evidencia empírica constatable sujeto a sujeto (Brenan, 1981; Puy Fraga, 1996: 43). Aun admitiendo esta realidad, la teoría del homo economicus racional y maximizador de beneficios será la base para conformar los elementos de su modelo óptimo de Constitución, pues no solo se proyecta metodológicamente sobre la teoría positiva del Estado, sino que este es explicado en su misma existencia a partir del reconocimiento apriorístico del valor del individuo (Vallespín, 1985: 207 y ss.). Para Buchanan la libertad es, en este sentido, la garantía del intercambio voluntario entre sujetos, el único que permite a estos dotar del valor que ellos desean a los bienes. Cualquier mecanismo de intercambio obligatorio o dirigido coarta la libertad en tanto anula la posibilidad al individuo de dotar valor de cambio, relativo, al objeto de las transacciones, distorsionando el mercado y los instrumentos a él inherentes. De ahí que el diseño institucional necesite hacerse desde y por la Constitución y con el objetivo de garantizar la cooperación voluntaria entre individuos maximizadores.

Así, Buchanan, acercándose a los austroamericanos de Mises y Hayek, entiende el mercado como catalaxia, es decir, como un orden espontáneo donde el conjunto alternativo de intercambios determina, sin necesidad de planificación o dirección alguna, los resultados económicos (Hayek, 2014: 
85-90). De este modo, tremolar la bandera de la catalaxia como orden espontáneo del mercado que garantiza la libertad humana le sirve a Buchanan para, siguiendo al mismo Hayek, demonizar cualquier intervención del Estado en la economía. Ningún agente, ni siquiera un «déspota bondadoso» (Buchanan, 1993: 121-125), podrá tener nunca toda la información de cada una de las valoraciones individuales de los bienes intercambiados ni de los propios procesos de intercambio que pueden operar en el mercado. Como quiera que existe esta incapacidad por parte del Estado de administrar los mecanismos de cooperación voluntaria, este ha de permitir que sean solo los agentes privados quienes, de acuerdo con la praxeología expuesta, potencien su libertad en el seno de los procesos de mercado, propiciando el contexto más funcional a la mayor expansión posible de las capacidades individuales. Y es que, huelga decirlo a estas alturas, el contexto normativo es esencial en tanto condiciona unos u otros intercambios voluntarios; de ahí que, de entre el conjunto alternativo de contextos, Buchanan elija aquel que sea menos invasivo y que mejor incorpore incentivos para la maximización (Puy Fraga, 1996: 170), aquel, en definitiva, que establezca un Estado limitado en lo económico desde lo jurídico, diferente, no obstante, del Estado mínimo. En la obra buchaniana, como estamos viendo, se reconoce la importancia del Estado y de su norma fundante y correlato, la Constitución, en la garantía de las condiciones de desenvolvimiento del libre mercado y de los derechos establecidos en el acuerdo originario, bases de la seguridad del intercambio, de ahí el especial cuidado que se presta en el diseño jurídico-estatal y en la toma en consideración de la relevancia de lo jurídico como elemento esencial de vertebración social. Pero, consciente de esta realidad que aleja cualquier postulación minarquista (como la de Nozick) ${ }^{3}$, Buchanan y la Escuela de Virginia se acercan a los postulados clásicos del liberalismo para centrar sus esfuerzos en la limitación jurídica del poder político. Al contrario de lo que permitía la «ilusión naturalista» del mercado en el XIX, tan bien denunciada en los albores del neoliberalismo, ahora se parte del giro ordoliberal para introducir desde el diseño constitucional límites expresos al Estado en su posible intervención expansiva en la economía. Se intentaría así, de este modo, alejar jurídicamente la posibilidad de que el reformismo social que integra las externalidades de un libre mercado «naturalizado» vuelva a anidar en el interior de los Estados contemporáneos, encontrando esta juridificación su mejor virtualidad en la Constitución fundada en

3 «La lucha social puede surgir hasta en el Paraíso. [...] En cualquier mundo que podamos imaginarnos estará presente la posibilidad de conflicto interpersonal, y por ello existirá la necesidad de definir y hacer cumplir los derechos individuales» (Buchanan, 2009: 46 y 47). 
el consenso unánime del momento constituyente. La norma fundamental se convierte en las «reglas del juego» que permiten la cooperación voluntaria de los individuos dentro de una estructura de incentivos asegurada por la existencia del Estado y por el cumplimiento de los derechos individuales asignados en el acuerdo preconstitucional (Brennan y Buchanan, 1987: 25).

\section{EL LEVIATÁN ADMINISTRATIVO}

La aplicación del homo economicus en la obra de Buchanan no es solo predicable del individuo aislado, sino también de la Administración en cuanto brazo ejecutivo del Estado. Para Buchanan, las mismas reglas catalácticas de decisión en el ámbito de los intercambios comerciales privados han de darse respecto de los bienes públicos, en tanto que dicha traslación sería la única que garantizaría la expansión del individualismo metodológico al análisis del Estado (Brennan y Buchanan, 1987: 14; Casas Pardo, 2011: 239). La constatación por parte de la Escuela de Virginia del aumento inconmensurable de la esfera estatal en el siglo Xx (Buchanan, 1993: 57-60), con el auge del Estado social de posguerra y de la expansión de la burocracia, los introduce en una tendencia ya consolidada de análisis de la Administración (Tullock, 1965), desde lo que podríamos llamar inmanentismo administrativo. Para Buchanan, la extensión del parámetro económico del individualismo anteriormente descrito a la burocracia hace de esta un monstruo tendente a la expansión continua de sus límites (Elósegui, 1993: 39-40). La Administración, dicen desde Virginia, no deja de estar compuesta por individuos maximizadores y racionales que buscan siempre el mayor beneficio personal, en su caso, la extensión de su capacidad de influencia. El burócrata es así descrito como un ser racional que busca la ampliación continua de los recursos que dispone en la medida en que estos son los que garantizan el afianzamiento de sus intereses personales. Cuanto más presupuesto y más medios personales, el burócrata más poder ostenta y más posibilidad tiene de satisfacer sus objetivos individuales, ya sean económicos, ideológicos o simbólicos (Buchanan, 1993: 102-104).

La Administración se convierte de esta forma en un Leviatán indómito sediento de presupuesto con el que poder aumentar los márgenes de su discrecionalidad (Atkinson, 1987: 13, y Puy Fraga, 1996: 273 y ss.). Además, al no recaer en los propios burócratas, dice Buchanan, la carga fiscal que engrosa los presupuestos de las administraciones, sino en el conjunto de los contribuyentes, la tendencia a la expansión se vuelve prácticamente irrefrenable. A la influencia que tienen las propias estructuras burocráticas en los legisladores (cfr. Niskanen, 2007) en procesos de bottom-up que se benefician del desconocimiento de estos últimos, hay que sumar la propensión de los representantes públicos a aumentar el gasto para satisfacer las demandas de los electores, cada 
vez más perfeccionadas, aumentando con ello el tamaño de la administración pública (top-down). Esta no deja de ser la materialización de los deseos de los gobernantes y de los electores, por lo que estaría expuesta a las mayorías que se turnaran en el poder y a sus volubles y cambiantes intereses.

Buchanan rechaza de plano que los mecanismos de restricción electorales (las elecciones periódicas) sean suficientes por sí mismos para constreñir las inclinaciones expansionistas de la Administración a manos de sus burócratas y de sus directores políticos (Downs, 1967). Primero, porque las secuencias temporales son diferentes, y al estar circunscritos los periodos electorales a un límite concreto (generalmente, cuatro o cinco años), los gobernantes triunfantes en los mismos no velarán por los resultados macroeconómicos a largo plazo, sino por la efectividad de las demandas electorales en el corto para poder asegurar, de este modo, la reelección (Buchanan, 1993: 119). En segundo lugar, la propia naturaleza política de las mayorías sociales que se alternan en el poder pueden utilizar este y, por ende, la expansión de la Administración, para implementar radicales programas de redistribución que les beneficien, y ello a costa de las minorías y de las élites económicas. El valor del individuo, protegido en el momento constituyente gracias a la regla de la unanimidad, quedaría así expuesto a la «rapiña» de los tentáculos de una Administración al servicio de las mayorías sociales.

Buchanan seguiría de este modo a lo formulado desde el corazón del liberalismo político por John Stuart Mill: «El interés del Estado está en una elevada presión fiscal; el de la comunidad, en pagar tan pocos impuestos como permita la cobertura de los gastos que necesita un buen gobierno" (2007: 215). Esta realidad, empíricamente demostrada para Buchanan, se ve insoslayable en la medida en que la existencia de bienes públicos que deben ser administrados por el poder político se vuelve necesaria. Recordemos que aquellos no solo existirían por ser monopolios naturales, sino también por estar vinculados a la salida, cohesionada y unánime, del estado de naturaleza. Tras el velo de incertidumbre que provoca el momento preconstitucional y la necesidad de compaginar la desigualdad de origen con la libertad individual proporcionada por la unanimidad, se presenta la exigencia de seguridad económica en torno a un mínimum de cohesión social articulada en bienes públicos que, como la misma seguridad, necesitan ser gestionados en la etapa postconstitucional. Pero, como vemos, para la public choice esa misma gestión devendrá en una continua expansión de sus propios medios, ampliando el margen de existencia de los bienes públicos y la proyección de estos sobre la economía y los criterios de distribución originarios. De suerte tal que su ampliación puede conllevar la tan temida coerción económica en los individuos a través de la introducción de instrumentos redistributivos y distorsionadores en el juego cataláctico, espontáneo, del libre mercado y sus medios de cooperación voluntaria. 
La paradoja se presenta de este modo con intensidad. El conflicto se cristaliza en el choque entre la necesidad de que el Estado no intervenga expansivamente en la economía para no distorsionar las potencialidades de la libertad individual en el mercado, por un lado, y la necesidad de articular la gestión y distribución de bienes públicos con el consiguiente peligro de su expansión mediante la hipertrofia de la administración burocratizada, por otro. La contradicción, inherente desde el mismo momento preconstitucional en el que se conforma unánimemente el modelo de convivencia, solo puede ser salvada, en Buchanan, a través del diseño constitucional de los mecanismos que administran esos bienes públicos. Solo la Constitución, con su virtualidad jurídica y su vinculatoriedad, puede neutralizar el conflicto preservando el contrato inicial fundado en la libertad de la desigualdad.

\section{LA SUPERACIÓN CONSTITUCIONAL DEL CONFLICTO: LÍMITES JURÍDICOS A LA INTERVENCIÓN DEL ESTADO EN LA ECONOMÍA}

Si algunos autores han visto en el constitucionalismo del Estado social de posguerra el intento de integrar el conflicto en el seno de la norma constitucional (De Cabo, 2010), podemos afirmar aquí que Buchanan ve en la Constitución el mejor instrumento para la superación de las contradicciones que provoca la articulación jurídica de la convivencia entre los principios antagónicos que se desprenden del modelo contractual ya analizado. En la obra del economista norteamericano, es desde el momento preconstitucional de la unanimidad wickselliana donde se deben proyectar, ex ante, aquellos mecanismos de control que se diseñen para frenar el expansionismo supuestamente inmanente de la Administración. Además, Buchanan constata en su modelo que el margen de maniobra de los individuos y sus intereses es más estrecho en el momento postconstitucional, una vez establecido el statu quo ${ }^{4}$ y legitimado el poder político, al contrario de lo que ocurre en el instante de la fundación del orden social, donde reina la unanimidad y donde, en consecuencia, cualquier interés individual, por aislado que sea, puede frenar al (futuro) Leviatán.

Partiendo nuevamente de su individualismo metodológico, Buchanan concluye que los individuos querrán neutralizar lo máximo posible la incertidumbre que se abre con la etapa postconstitucional. Tomando como hipótesis

4 Buchanan define el statu quo como «el conjunto completo de expectativas compartidas referentes a los dominios conductuales de los miembros individuales de la comunidad, de las diversas coaliciones y de los grupos de individuos organizados, incluida la entidad política, el Estado» (Buchanan, 2009: 134). 
la de un individuo privilegiado económicamente en el momento de la negociación del pacto fundante del orden social, el premio Nobel deriva la conveniencia de que ese individuo tenga la certeza en todo momento de que su situación no se va a ver perjudicada arbitrariamente por las futuras mayorías que se alternen en el poder. Para lograr el consenso unánime que está en la base de un acuerdo verdaderamente democrático, nos dice Buchanan, se precisa el establecimiento apriorístico, desde el mismo acuerdo, de límites concretos y rotundos a la acción estatal para evitar que esta, aprovechando la administración de los bienes públicos que tiene encomendada, pueda llevar a cabo procesos injustos de redistribución que alteren el orden de libertad originario. El velo de incertidumbre es aquí utilizado para la justificación de la incorporación constitucional de sanciones y ataduras a las futuribles voluntades políticas postcontractuales, mediante la juridificación del precompromiso elsteriano al más alto nivel. Ahora bien, si se admite esta necesidad de proyectar desde lo constitucional-constituyente los límites al poder político (y sobre todo, como veremos, en su vertiente económica), ¿bajo qué parámetro debe hacerse?

\section{WORST CASE SITUATIONS: HIPÓTESIS LEVIATÁN}

Siguiendo a parte de la tradición liberal, desde Hume a Madison o Stuart Mills, Buchanan establecerá el criterio de que las limitaciones que se impongan al poder político desde el momento constituyente han de ser pensadas, en todo momento, para la "peor de las situaciones posibles». El temor liberal a la expansión del Estado se ve aquí cristalizado en el diseño de las normas atendiendo a la peor parte del abanico de posibilidades que se abren con la constitución del orden social. Así se evitarían en un futuro, dice Buchanan, pérdidas en las funciones de preferencias individuales desproporcionadas. Anticipándose a las posibles extralimitaciones políticas, la Constitución prevé de antemano las peores y activa los mecanismos precautorios o sancionadores que correspondan. El miedo a la potencialidad del Estado se deriva en Buchanan de su consideración pragmática de la realidad. Al ser filosóficamente y ad intra un libertario «inacabado» o ridens, como él mismo siempre reconoció, considera al Estado como un mal necesario, pero un mal de todos modos, que

5 «El verdadero principio de un gobierno constitucional exige que se presuma que se abusará del poder político para alcanzar los objetivos particulares de quien lo detenta, no porque siempre sea así, sino porque ésa es la tendencia natural de las cosa, y en la protección contra esto radica la utilidad específica de las instituciones libres», cit. en Brennan y Buchanan (1987: 38). 
ha de ser constreñido lo máximo posible para que puedan operar en libertad los mecanismos de cooperación voluntaria que se dan en el libre mercado (lo más cercano, en este sentido, a su ideal personal libertario). Entre la anarquía y el Leviatán, siguiendo la formulación de su famosa obra, caben los límites a la libertad dentro de un marco mismo de libertad. Pero este marco está diseñado y pensado ex ante sobre el temor a que el Estado se convierta en un Leviatán al utilizar los medios postconstitucionales, de ahí que el modelo actúe con contundencia en la articulación jurídica de las limitaciones. Atar desde la Constitución a un Leviatán dormido que en cualquier momento puede despertarse y vulnerar el pacto unánime que le da legitimidad: ese es el objetivo.

En este sentido, al tener la Constitución una tendencia a la estabilidad temporal, la incorporación a priori de limitaciones a la expansión del poder que ella misma instituye, desde la aversión al riesgo que se le presupone a los individuos que abandonan el estado de naturaleza, encaja perfectamente con la imputación de racionalismo que a estos se realiza. Además, la necesidad ya vista de que existan bienes públicos y de que el Estado tenga que producirlos y administrarlos no conlleva, necesariamente, que las decisiones postconstitucionales de ese Estado se adecúen a la función de preferencias individuales, pudiendo, como decimos, convertirse en un Leviatán indómito (Buchanan, 1993: 109).

Evidentemente, el establecimiento de restricciones basadas en situaciones worst case conlleva unos costos políticos y económicos enormes ${ }^{6}$. En efecto, si el modelo (la Constitución y el Estado de ella resultante) se diseñan partiendo de un optimismo antropológico, sin proyectar limitaciones al poder de Estado, este puede devenir en una potenciación de las tendencias cooperativas de la sociedad y en un aumento generalizado del bienestar de los individuos que la componen, puesto que no tiene enfrente diques que contengan y constriñan su acción. No obstante, y aquí reside uno de los ejes centrales en el pensamiento de Buchanan, los costes que se producirían como consecuencia de una desviación o distorsión de ese comportamiento idílico serían más que proporcionales a los costes que se derivan del establecimiento de restricciones

6 Esta previsión de la Constitución para las peores situaciones posibles que puedan darse en su seno es descrita por el propio Buchanan de esta forma tan prosaica: «Puede ser empíricamente difícil contrastar la hipótesis de que habrá una riada, en una determinada localidad, con una probabilidad de 0,01 cada año. Sin embargo, la teoría de la que se desprende tal hipótesis de predicción puede ser utilizada como la base normativa para tomar las precauciones encaminadas a evitar el desastroso daño de la riada» (Brennan y Buchanan, 1987: 40). 
constitucionales ex ante. La posibilidad de que unos pocos individuos no participen del altruismo y de que, con su voluntad, obliguen al resto a abandonar las posiciones cooperativas, le hace a Buchanan alejarse de todo optimismo antropológico y seguir aquí, una vez más, el referente de Hobbes. Si la Constitución lato sensu no incorpora mecanismos de restricción al poder político, aun cuando este pueda ser la extensión de las más benéficas virtudes del ser humano, las consecuencias de una perversión del Estado pueden ser, simplemente, catastróficas y anunciar la instauración de un Leviatán sin límites, con lo que ello supondría para la garantía de la libertad individual. Como resume Puy Fraga: «Las eventuales pérdidas de eficacia por un control riguroso de la autoridad pública se compensan con creces ante la eventualidad de que la propia autoridad explote su posición en contra de los deseos y preferencias del conjunto de los ciudadanos» (1996: 181-182).

\section{LOS LÍMITES AL PODER FISCAL DEL ESTADO}

Para Buchanan, el conjunto de restricciones constitucionales impuestas en el marco institucional condiciona el nivel de libertad que disfrutan los individuos en la etapa postconstitucional. Y como quiera que, en su ideario individualista, el valor de la libertad de aquellos reside en el pleno disfrute de su propiedad (la propierty de Adam Smith) y en el intercambio de los bienes inherentes a ella mediante mecanismos de cooperación voluntaria, la defensa y protección de esa esfera constituye un objetivo de primer orden en el paradigma contractualista del autor norteamericano. La libertad vinculada a la garantía de la desigualdad originaria ya expresada en el equilibrio de poder preconstituyente y traslucida en el pacto societatis, bien primario por excelencia del liberalismo político, es aquí protegida al más alto nivel jurídico mediante la restricción de aquel poder que podría distorsionarla: el fiscal (Buchanan, 2009: 82 y ss.).

En efecto, la vertiente intervencionista del Estado en la economía es reducida, en el contractualismo buchaniano, a la administración de un conjunto limitado de bienes públicos, pero que deben ser financiados con mínimos instrumentos fiscales de recaudación e, incluso, de redistribución. En la medida en que estos pueden extralimitarse en el momento postconstitucional y romper con el unánime precompromiso contractual, deben establecerse desde este contundentes mecanismos de restricción fiscal y, por ende, presupuestaria, que garanticen la vigencia de la cooperación voluntaria y el alejamiento del intervencionismo distorsionador en esta. El verdadero "peligro» del expansionismo del Estado y de la Administración reside, en consecuencia, en los instrumentos fiscales y presupuestarios que dan cobertura financiera a la gestión de los bienes públicos. Y sobre ellos deberán recaer, por tanto, la 
aplicación de la hipótesis hobbesiana y la consiguiente imposición de límites constitucionales diseñados desde el apriorismo constituyente.

En este sentido, si al inmanentismo de la expansión administrativa en el Estado contemporáneo analizado por Tullock y Buchanan tenemos que sumarle la aplicación de la hipótesis hobbessiana, se entenderá la intensidad de los límites diseñados y su naturaleza vinculante y supralegal. El poder fiscal se entiende como su correlato administrativo, es decir, como un potencial Leviatán que tiende a la expansión y al aumento constante de la carga impositiva para saciar sus necesidades presupuestarias y perpetuar su influencia; a costa, por añadidura, de los bienes y las propiedades de los individuos y, preferentemente, de aquellos que gozan de mejor posición económica.

Para neutralizar jurídicamente en la Constitución económica el conflicto anteriormente descrito, esta se yergue en puente de conexión entre los deseos precontractuales de los individuos y la aplicación política de aquellos a través de la Administración. La reducción de la incertidumbre y de la posibilidad de reactivación del Leviatán durmiente, deseada en el pacto fundante, se vertebra a través de este con la constitucionalización de mecanismos institucionales ad hoc que frenan la expansión del poder fiscal. Así, en la obra de Buchanan, la parte económica de la Constitución reviste una notoria extensión y sus tentáculos llegan a todos los rincones de la fiscalidad y del control presupuestario. Buchanan se convierte de este modo en un ferviente admirador de la efectividad constitucional y de su carácter invasivo, a pesar de que precisamente esta incidencia y rigidez en la esfera de lo decidible políticamente en economía puede restringir per se la propia esfera de libertad que él mismo intenta potenciar. Sea como fuere, dentro del programa de la economía constitucional se defiende una amplitud considerable de mecanismos constitucionales de control del poder político en su vertiente fiscal y presupuestaria (Brennan, 1981: 466 y ss.).

En primer lugar, Buchanan encuentra en la configuración clásica del Estado de derecho algunos de los expedientes jurídicos que son funcionales a la limitación del poder fiscal, como el principio de generalidad impositiva, el de igualdad o el de legalidad. En efecto, se es consciente de la estrecha vinculación que siempre ha existido entre el desarrollo de los principios generales del Estado constitucional y el deseo de someter al poder fiscal desde la garantía del orden económico liberal. No es de extrañar que al origen mismo de los Estados Unidos esté tan ligado a la reivindicación fiscal («No Tax without Representation»), trasunto de la defensa de la propiedad privada frente a un pretendido expolio del poder político (cfr. Blanco Valdés, 2006, y Brinton, 1965: 28-39). Uno de los artefactos propios del Estado constitucional, como la celebración de elecciones periódicas y la alternancia en la representación, también puede servir para limitar los excesos fiscales del Estado, pero, como 
vimos, la propia naturaleza de las elecciones, su carácter servil para con los intereses momentáneos de las mayorías sociales y su poca previsibilidad respecto a periodos posteriores (largo plazo), impiden su consideración como mecanismo principal de limitación.

De aquí que Buchanan y la Economía constitucional busquen mecanismos más incisivos y explícitos de control del poder fiscal que puedan proyectarse desde la Constitución como pacto unánime que legitima y reconoce la existencia de un catálogo de bienes públicos que ha de ser administrado. Aplicada la hipótesis hobbesiana del worst case, el fundador de la Escuela de Virginia aboga por la limitación explícita del déficit y el endeudamiento públicos en la Constitución, el freno al poder recaudatorio mediante la instauración de un fuerte federalismo fiscal descentralizador y la incorporación de mecanismos de democracia semidirecta para la elección de las bases impositivas (cfr. Buchanan y Wagner, 1977).

En cuanto a estos dos últimos instrumentos, no nos debe extrañar en el planteamiento holístico de Buchanan su incardinación y defensa. La democracia semidirecta, implementada a través de los referendos, no es extraña al corpus de Virginia, ya que encuentra su fundamento en el individualismo metodológico y la defensa a ultranza de la neutralidad de los procedimientos de decisión pública en los que participen todos los individuos. Buchanan pone como ejemplo paradigmático la «rebelión del contribuyente» que se produjo en California con la aprobación de la famosa Proposición 13 (Brennan y Buchanan, 1987: 51 y ss.). En 1978, y aprovechándose de la tradición de democracia semidirecta que siempre ha tenido California, el cuerpo electoral de este Estado aprobó la iniciativa de limitar constitucionalmente las subidas de impuestos a un tanto por ciento del valor del hecho imponible y de incorporar en la Constitución estatal la exigencia de mayorías cualificadas para la modulación de impuestos (cfr. Cain y Noll, 2010). En este sentido, Buchanan también es un firme partidario de acercar lo más posible los procedimientos de decisión pública en materia impositiva al consenso preconstitucional, aun siendo consciente de que ello se hace dentro del margen representativo del statu quo postconstitucional y que la unanimidad, aquí, conllevaría un costo inasumible. Intentar elevar al más alto rango de protección política mediante la juridificación de la exigencia de mayorías cualificadas y el reconocimiento de mecanismos de democracia semidirecta en la aprobación o modificación de los impuestos, se ve así como una mayor garantía de la seguridad frente al vaivén cambiante de las mayorías (Buchanan, 2009: 134 y ss.).

Por su parte, la potenciación del federalismo supondría la fragmentación del poder fiscal y su descentralización. Buchanan parte de la concepción liberal de que una de las mejores salvaguardas frente a la tiranía del poder y su posible extralimitación reside en la propia división interna de este, alejando la 
posibilidad de que su concentración (jacobinismo) devenga en rupturas o cambios bruscos que dañen la seguridad jurídica de la libertad (y la propiedad) de los individuos. En sus propias palabras: «las pérdidas de oportunidad individuales aumentan a medida que se incrementa la centralización en el sector público» (Buchanan, 2009: 155). La defensa que hace la Escuela de Virginia del federalismo fiscal se mueve en este parámetro de limitación del poder, en un país, recordemos, donde la tradición federal está muy arraigada en el andamiaje constitucional. A fortiori, Buchanan encuentra un argumento aún más contundente para la defensa del federalismo. Este no solo acerca las decisiones en materia fiscal al conjunto de los individuos, no solo supone una división del poder tributario y su consiguiente debilitamiento frente a posibles tentativas expansionistas desde el centro, sino que también puede crear un marco institucional propio para la competencia fiscal entre territorios. Al dividir la potestad tributaria entre Estados, en un contexto, como el norteamericano, de libertad de establecimiento y de capitales, los respectivos gobiernos tenderán inevitablemente a competir para atraer mayores cuotas de capital, desterrando cada vez con más intensidad la posibilidad de incurrir en excesos tributarios. El dumping fiscal se convierte de este modo en una garantía de la libertad y de su consustancial correlato, la propiedad privada como expresión de la función de preferencias individuales, en el pensamiento de Buchanan (Brennan y Buchanan, 1987: 231).

Respecto a la incorporación en la Constitución de límites expresos de déficit y endeudamiento públicos, el teórico de la economía constitucional sigue la misma lógica precedente, a la que añade, no obstante, una crítica basada en un puro criterio de democraticidad. Por su evidencia, no solo un límite concreto a la expansión de la Administración pública y del Estado debe centrarse en su capacidad presupuestaria (déficit y deuda), sino que la restricción de la capacidad de endeudamiento del poder político supone una garantía democrática de primer orden por cuanto intenta ajustar el periodo electoral a la previsión a largo plazo. En efecto, niveles excesivos de deuda pública coartan la libertad individual en la medida en que financian el expansionismo de la intervención del Estado en la economía (potenciación de los bienes públicos) y, con ello, introducen elementos distorsionadores en el orden de libertad cataláctico. Pero es que, además, un endeudamiento excesivo ata a las futuras generaciones al pago de un expansionismo sobre el que ellas no han participado, perjudicando no solo al conjunto de individuos del periodo electoral donde se ha tomado la decisión, sino también a aquellos de periodos subsiguientes (Buchanan, 1993: 191-197 y 1991: 199-206). En palabras de Brennan y Buchanan, «el poder de endeudamiento implica que el gobierno maximizador de los ingresos, con el poder en sus manos pero sin la previsión de su continuidad en él, puede, a través del endeudamiento, apropiarse del valor total de los ingresos impositivos de todos los periodos futuros, incluidos 
aquellos en los que tal Leviatán no gobierne» (1987: 141). La falta de previsión como consecuencia del cortoplacismo de las necesidades electorales de los gobernantes tiene su mayor cristalización, siguiendo de nuevo el argumento buchaniano, en el sobreendeudamiento que ahoga la capacidad presupuestaria del Estado y alienta la ficción de su expansión continua. La constitucionalización de contundentes límites al déficit y a la deuda pública («que han de ser particularmente severos», según Buchanan) introduce por tanto un elemento corrector desde lo jurídico-constitucional a los excesos políticos, y de nuevo proyecta los intereses de la totalidad unánime de la individualidad desde el momento constituyente a las decisiones postcontractuales.

No obstante la coherencia que guarda esta última elaboración con los fundamentos teóricos de Buchanan, su concreción se debe a la tradición ya existente de constitucionalización de la estabilidad presupuestaria en el marco de los Estados federados norteamericanos, tradición de la que el de Virginia bebe directamente (Poterba, 2006). Aunque desde los inicios de la joven república estadounidense se planteó la posible necesidad de limitar constitucionalmente el déficit y la deuda pública, tal exigencia solo consiguió plasmarse, a lo largo del siglo XIX y al calor de las continuas crisis presupuestarias de los Estados (sobre todo, la de 1837), a nivel estatal y no federal (Seto, 1997: 1467 y ss.). La poca entidad de la Administración central decimonónica en los Estados Unidos, la propia concepción que se tenía de la misma desde la famosa polémica entre republicanos y federalistas, así como la práctica ausencia de déficits excesivos a nivel nacional exceptuando los periodos de guerra, habían creado el contexto propicio para que la preocupación por la capacidad presupuestaria y financiera de la Federación quedara relegada a un segundo plano (Krishnakumar, 2005: 140-145). Los Estados, en cambio, intentando recuperar la confianza de los inversores tras los sucesivos defaults que se produjeron en la primera mitad del XIX (Davis y Cull, 1993), habían ido recogiendo en sus respectivas Constituciones la previsión que ya esbozara sucintamente Jefferson durante los primeros años de existencia del país, y estableciendo en consecuencia límites constitucionales al endeudamiento y la expansión del déficit (Hou y Smith, 2006: 32-43). Hasta el New Deal y el surgimiento del sui generis welfare state norteamericano, el grueso del gasto público descansaba en los brazos de los Estados, pero con el nuevo escenario que se inaugura en la posguerra, la preocupación por la expansión de la Administración federal y los consiguientes déficits excesivos que trae aparejados se revitaliza desde el prisma de las limitaciones constitucionales que ya estaban establecidas en casi todos los Estados. De ahí que desde entonces, desde que el senador Knutson presentara en 1936 un proyecto de enmienda a la Constitución federal, las iniciativas para reformar esta e incorporar una restricción jurídicoconstitucional al endeudamiento y al déficit excesivo se sucedieran (cfr. Savage, 1988). Pero no será hasta la década de los años setenta, con el clima creciente de 
desafección política que recorrería Estados Unidos (guerra de Vietnam incluida) y con la irrupción de la crisis del petróleo, cuando dicha preocupación cobrará especial relevancia. Los intentos de reforma constitucional vía artículo V se incrementaron, e incluso se estuvo a punto de convocar la primera convención constitucional de la historia estadounidense desde la aprobación de la Constitución, al requerir numerosos Estados su convocatoria (Morgan, 1988: 422 y ss.). El contexto de la «rebelión del contribuyente» y su triunfo en California con la Proposición 13 coadyuvó en la articulación de un verdadero movimiento social y político, con presencia de destacados políticos, tanto republicanos como demócratas, en torno a la necesidad de trasladar las previsiones estatales ya indicadas a la Constitución federal y poner freno así a la expansión de Washington (Kyvig, 1998: 104). En este movimiento, en el que cobraría especial importancia la National Taxpayers Union, Buchanan haría aportaciones destacadas desde su teoría y, con esta, ampararía académicamente la pretensión (Buchanan y Wagner, 1977). No obstante, a pesar de todos los esfuerzos, ni la convención constitucional llegó a reunir los requerimientos estatales necesarios en su día ni el Congreso ha llegado nunca a aprobar una enmienda a la Constitución para incorporar la restricción al déficit y a la deuda pública, a pesar de que ha habido ocasiones en que tal enmienda ha estado a punto de conseguir el consenso suficiente, sobre todo en 1995 (Buchanan, 1995; 1993: 52-53).

Buchanan y la economía constitucional, por tanto, no solo tuvieron esta vez un asidero fáctico al que poder agarrarse, como el que constituían los límites constitucionales que ya se daban previamente en las experiencias estatales desde el siglo XIX, sino que pudieron verter sus proposiciones normativas, fundadas tanto en la visión neocontractualista como en las perspectivas societales ya analizadas, en el intenso debate que en los años setenta y principios de los ochenta se dio a nivel federal. Y aunque finalmente tales pretensiones nunca consiguieron vencer los celos del establishment de Washington y quedaron en meros intentos, estos no dejan de constituir precedentes indispensables en los que cualquier aproximación a la problemática constitucional de la limitación del poder fiscal del Estado puede sumergirse. La teoría de Buchanan se ve así enriquecida por la praxis más inmediata, que a su vez se ve nutrida del enorme edificio doctrinal del autor estadounidense, en un proceso dialógico que de nuevo refuerza la complejidad y la pretensión de globalidad del programa de la economía constitucional.

\section{CONCLUSIÓN}

Como hemos tenido oportunidad de ver, el giro analítico hacia el Estado y la imputación a este de la salvaguarda última del libre mercado, que comienza 
con el parteaguas (neo)ordoliberal de posguerra, es completado por la public choice del economista James M. Buchanan y la elaboración, por su parte, de una compleja teoría de la realidad jurídico-estatal que se cimienta en una visión neocontractualista del origen de la res publica. El análisis de toda la realidad social desde el prisma del individualismo metodológico, que se proyecta desde el comportamiento humano en su conjunto a la actividad y naturaleza misma de la Administración pública, lleva al planteamiento buchaniano a un hard case donde entran en conflicto el valor de la libertad individual cristalizada en la desigualdad de la posición original, por un lado, y, por otro, la tendencia inmanente del Estado a su propio expansionismo, sirviéndose de la administración de los bienes públicos. De hecho, es la constatación de la necesidad de estos lo que provoca la mayor parte de las preocupaciones de la economía constitucional y sobre la que se nutren sus elaboraciones más prescriptivas. La derivación de la existencia de bienes públicos del velo de la ignoracia rawlsiano y de la urgente precisión de alcanzar un pactum societatis, que otorgue además seguridad a la distribución de derechos, implica en el programa de la public choice la búsqueda incesante de mecanismos a través de los cuales pueda asegurarse la libertad individual y su respeto. La relevancia de la regla de la unanimidad, tomada del economista Wiksell, se condensa en el momento constituyente para garantizar una situación de equilibrio jurídico respetuosa, al máximo, con las desigualdades iniciales y con las respectivas asignaciones de bienes a los individuos.

Establecido así como objetivo esencial el aseguramiento de la propiedad privada y el libre intercambio de los bienes inherentes a ella como la mejor plasmación de la libertad, el orden jurídico que nace del pacto fundante ha de basarse en su autolimitación consciente (precompromiso elsteriano) para poder crear el contexto normativo más adecuado al desenvolvimiento de los mecanismos de cooperación voluntaria. La protección desde lo jurídico, con su constreñimiento, del orden espontáneo del mercado cataláctico, se yergue en una necesidad democrática para Buchanan en cuanto ello posibilita la defensa a ultranza de la libertad y del valor individuales. Como quiera que ambos se expresan más resueltamente y de manera íntegra en el momento constituyente a través del consenso, este ha de proyectarse desde la unanimidad inicial al diseño de dicho contexto normativo postcontractual para evitar con su juridificación las posibles extralimitaciones de los poderes establecidos. Estos, por su parte, y como ya hemos indicado, tienen por objeto la administración de los bienes públicos y tienden irremediablemente a su propia expansión debido a la continua maximización de los intereses burocráticos y de la subordinación de los gestores públicos a las necesidades electorales, por lo que se les ha de aplicar con mayor énfasis las restricciones ex ante de los procedimientos postcontractuales. La Constitución, convertida en el medio a 
través del cual la unanimidad constituyente se "protege» del futurible Leviatán que ella misma crea, ha de recoger en consecuencia fuertes ataduras a la actuación de los poderes públicos $\mathrm{y}$, sobre todo, a su actuación fiscal y presupuestaria. Para Buchanan y la economía constitucional, el expansionismo de la Administración, y por ende el peligro que este conlleva para la propiedad y las expectativas individuales, se centra en el constante aumento presupuestario de las agencias gubernamentales, de ahí la conveniencia de imponer desde la Constitución un modelo de federalismo competitivo, mayorías sobrecualificadas para la determinación de las bases imponibles o contundentes límites al gasto y al endeudamiento público; estos últimos, además, siguiendo las experiencias estatales en Estados Unidos ya trazadas con anterioridad.

La justificación teórica de estos mecanismos, realizada en primer lugar y de manera más rigurosa desde la economía constitucional del autor aquí analizado, y que se asienta en la visión holística de la realidad social anteriormente descrita, cobra hoy especial relevancia en la medida en que la Unión Europea y no pocos Estados miembros han constitucionalizado en los últimos años tales instrumentos de "gobernanza» para hacer frente a la coyuntura económica. Buena parte de las medidas que Buchanan y su Escuela de Virginia propusieron a partir de 1970, a veces asentadas en la propia praxis estadounidense, y que han obtenido posteriormente respaldo en amplios sectores académicos, son hoy realidad normativa, ya sea desde la atalaya del proceso de integración europeo o desde los baluartes constitucionales de los Estados. La introducción de las restricciones jurídico-constitucionales defendidas por Buchanan en el seno de las democracias europeas y de sus modelos económicos parece ser solo el comienzo de un largo camino que seguirá modificando, sustancialmente, la idea clásica de "constitución económica» y cuyas consecuencias, desde el paradigma constitucional y democrático, aún no pueden analizarse en su totalidad.

\section{Bibliografía}

Álvarez Conde, E. y Souto Galván, C. (coords.) (2012). La constitucionalización de la estabilidad presupuestaria. Madrid: Universidad Rey Juan Carlos.

Atkinson, A. B. (1987). James M. Buchanan's contributions to economics. Scandinavian Journal of Economics, 89 (1), 5-15. Disponible en: https://doi.org/10.2307/3440481.

Blanco Valdés, R. (2006). El valor de la Constitución: separación de poderes, supremacía de la ley y control de constitucionalidad en los origenes del Estado liberal. Madrid: Alianza Editorial.

Bonefeld, W. (2013). Adam Smith and ordoliberalism: On the political form of market liberty. Review of International Studies, 39 (2), 233-250. Disponible en: https://doi.org/10.1017/ S0260210512000198.

Brennan, G. (1981). Tax limits and the logic of constitutional restrictions. En H. Ladd y A. Brennetot (2015). The geopraphical and ethical origins of neoliberalism: The Walter 
Lippmann Colloquium and the foundations of a new geopolitical order. Political Geography, 49, 30-39. Disponible en: https://doi.org/10.1016/j.polgeo.2015.06.007.

- y Buchanan, J. M. (1987). El poder fiscal. Fundamentos analiticos de una constitución fiscal. Madrid: Unión Editorial.

Brinton, C. (1965). The Anatomy of Revolution. New York: Vintage Books.

Buchanan, J. M. (1974). The machinery of freedom: guide to a radical capitalism, de David Friedman. Journal of Economic Literature, 12, 914-915.

- (1975). Utopia, the Mininal State, and entitlement. Public Choice, 23 (1), 121-126. Disponible en: https://doi.org/10.1007/BF01718099.

— (1987). La razón de las normas. Madrid: Unión Editorial.

- (1991). La ética del cumplimiento del pago de la deuda. Hacienda Pública Española, 3 (119), 199-206.

(1993). Economía constitucional. Madrid: Instituto de Estudios Fiscales.

- (1995). Clarifying confusion about the Balanced Budget Amendment. National Tax Journal, 48 (3), 347-355.

- (2009). Los límites de la libertad. Entre la anarquía y el Leviatán. Madrid: Katz Editores.

- y Wagner, R. E. (1977). Democracy in Deficit. New York: Academic Press.

Bush, W. y Mayer, L. (1973). Some implications of anarchy for the distribution of property. Virginia: Center for Study of Pulic Choice.

Cain, B. y Noll, R. (2010). Institutional causes of California's Budget Problem. Stanford Institute for Economic Policy Research, 2 (3).

Casas Pardo, J. (2011). La filosofía económica de James M. Buchanan. Anuario filosófico, 44 (2), 233.

Davis, L. y Cull, R. (1993). International Capital Movements and American Economic Growth 1820-1914. En S. Engerman y R. Gallman (eds.). The Cambridge Economic History of the United States. New York: Cambridge University Press.

De Cabo, C. (2010). Dialéctica del sujeto, dialéctica de la Constitución. Madrid: Trotta.

Downs, A. (1967). Inside bureaucracy. Boston: Little Brown.

Elósegui Itxaso, M. (1993). El contractualismo constitucionalista de James Buchanan. Anuario de Filosofía del Derecho, 10, 33-58.

Elster, J. (2009). Ulises desatado: estudios sobre racionalidad, precompromiso y restricciones. Barcelona: Gedisa.

Enériz Sánchez, N. (2013). El Tratado de Estabilidad, Coordinación y Gobernanza en la Unión Europea y Monetaria. Unión Europea Aranzadi, 12.

Erhard, L. (1994). Economía social de mercado: su valor permanente. Madrid: Ediciones Rialp. Escalante Gonzalbo, F. (2016). Historia mínima del neoliberalismo. Madrid: Editorial Turner. Gauchet, M. (2007). La crise du liberalism. Paris: Gallimard.

Gerber, D. (1994). Constitutionalizing the Economy: German Neoliberalism, Competition Law and the "New Europe». The American Journal of Comparative Law, 42 (1), 25-84. Disponible en: https://doi.org/10.2307/840727.

Hayek, F. A. (2011). Camino de servidumbre. Madrid: Alianza Editorial.

- (2014). Los fundamentos de la libertad. Madrid: Unión Editorial.

Hoevel, C. (2014). Las contradicciones culturales del neoliberalismo. Economía y Política, 1 (2), 39-72. 
Hogarty, T. (1972). Cases in anarchy. En G. Tullock (ed.). Explorations in the theory of anarchy (pp. 51-64). Virginia: Center for Study of Public Choice.

Hou, Y. y Smith, D. (2006). Framework for understanding State balanced budget requirement systems: Reexamining distintive features and an operational definition. Public Budgeting and Finance Review, 26 (3), 22-45. Disponible en: https://doi.org/10.1111/ j.1540-5850.2006.00853.x.

Jackson, B. (2010). At the origins of neo-liberalism: The free economy and the Strong State, 1930-1947. The Historical Journal, 53 (1), 129-151. Disponible en: https://doi. org/10.1017/S0018246X09990392.

Krishnakumar, A. (2005). In defense of the debt limit statute. Harvard Journal on Legislation, 42, 135.

Kyvig, D. (1998). Refining or Resisting Modern Government? The Balanced Budget Amendment to the US Constitution. Akron Law Review, 28, 97.

Laval, C. y Dardot, P. (2013). La nueva razón del mundo. Barcelona: Gedisa Editorial.

Lippmann, W. (2014). The Good Society. Ulan Press.

Marcos de la Fuente, J. (1978). La economía social de mercado. Madrid: Unión Editorial.

Martínez García, J. I. (1985). La teoría de la justicia de Justicia en John Rawls. Madrid: Centro de Estudios Constitucionales.

Mill, J. Stuart (2007). Del gobierno representativo. Madrid: Tecnos.

Mitcher, W. C. (1987). The Calculus of Consent: Notes in retrospection. En C. K. Rowley (comp.). Democracy and Public Choice. Oxford: Basil Blackwell.

Morgan, I. (1988). Unconventional politics: the campaign for a balanced budget amendment. Constitutional Convention in the 1970s. Journal of American Studies, Cambridge University Press, 32 (3), 421-445.

Musgrave, R. A. (1993). Comentario a Brennan. Hacienda Pública Española, 124, 201-205.

Niskanen, W. (1975). Bureaucrats and politicians. Journal of Law and Economics, 18, (3), 617643. Disponible en: https://doi.org/10.1086/466829. (2007). Bureaucracy and representative government. Chicago: Aldine Transaction.

Nozick, R. (1988). Anarquía, Estado y utopía. México: Fondo de Cultura Económica.

Pastore, M. (2012). Neocontractualismo y liberalismo político: el acuerdo racional y sus críticas, Colección, 17 (22).

Pérez Bermejo, J. M. (2000). Diferencias internas en la teoría moral de la justicia como acuerdo: Hobbes y Buchanan a propósito de la igualdad. Revista de Filosofía, 24, 217-245.

Porras Nadales, A. J. (1984). Contractualismo y neocontractualismo. Revista de Estudios Politicos, 41, 15-41.

Poterba, J. M. (2006). Balanced Budget Rules and Fiscal Policy: Evidence From the States. National Tax Journal, 48 (3), 329-336.

Puy Fraga, P. (1996). Economía política del Estado constitucional. Fundamentos de la Economía constitucional. Barcelona: Cedecs Editorial.

Rawls, J. (1979). Teoría de la justicia. Madrid: Fondo de Cultura Económica de España.

Rothbard, M. (1973). For a new liberty. New York: Macmillan.

Savage, J. D. (1988). Balanced Budgets and American Politics. New York: Cornell University Press. 
Seto, T. (1997). Drafting a Federal Balanced Budget Amendment That Does What It Is Supposed To Do (And No more). The Yale Law Journal, 106, 1449. Disponible en: https://doi.org/10.2307/797187.

Spencer, H. (1984). El individuo contra el Estado. Barcelona: Editorial Orbis.

Tideman, T. (ed.). Tax and expenditure limitations. Washington: The Urban Institute Press.

Tullock, G. (1965). The politics of bureaucracy. Washington: Public Affairs Press.

- y Buchanan, J. M. (2015). El cálculo del consenso. Madrid: Aranzadi.

Vallespín Oña, F. (1985). Nuevas teorías del contrato social: John Rawls, Robert Nozick y James Buchanan. Madrid: Alianza Editorial.

Vanberg, V. J. (1988). «Ordnungstheorie» as constitutional economics. The German conception of a social market economy. ORDO: Jahrbuch für die Ordnung von Wirtschaft und Gesellschaft, 39, 17-31.

- (2005). Market and state: the perspective of constitutional political economy. Journal of Institutional Economics, 1 (1), 23-49. Disponible en: https://doi.org/10.1017/ S1744137405000032.

- (2014). James M. Buchanan's contractarianism and modern liberalism. Constitutional Political Economy, 25 (1), 18-38. Disponible en: https://doi.org/10.1007/s10602-014-9152-4. 